\title{
Synthesis of Au/C Catalysts by Ultrasonic-Assisted Technique for Vinyl Chloride Monomer Production
}

\author{
Wiboon Wittanadecha ${ }^{1}$, Navadol Laosiripojana ${ }^{2}$, Anawat Ketcong ${ }^{3}$, Niwat Ningnuek ${ }^{3}$, \\ Piyasan Praserthdam ${ }^{1}$, and Suttichai Assabumrungrat ${ }^{1} *$ \\ 1 Center of Excellence in Catalysis and Catalytic Reaction Engineering, Department of Chemical \\ Engineering, Faculty of Engineering, Chulalongkorn University, Bangkok 10330, Thailand \\ 2 The Joint Graduate School of Energy and Environment, King Mongkut's University of Technology \\ Thonburi, Bangkok 10140, Thailand \\ 3 Thai Plastic and Chemicals Public Company Limited, Bangkok 10120, Thailand. \\ *Email: Suttichai.A@chula.ac.th (Corresponding author)
}

\begin{abstract}
In the present work, the ultrasonic-assisted technique is applied to synthesize $\mathrm{Au} / \mathrm{C}$ catalysts for vinyl chloride monomer (VCM) production via acetylene hydrochlorination. The catalytic performance of the obtained catalysts is compared with that of the catalyst prepared by a conventional incipient wetness impregnation technique. It was found that all the prepared catalysts show high VCM selectivity $(>99.5 \%)$. The use of the ultrasonic-assisted technique can significantly improve the catalytic activity and stability of the synthesized $\mathrm{Au} / \mathrm{C}$ catalysts. An ultrasonic driven time of 6 hours is found to be a promising catalyst for commercial application regarding the catalyst stability. In addition, the effect of operating parameters is investigated. Suitable operating temperature and $\mathrm{HCl} / \mathrm{C}_{2} \mathrm{H}_{2}$ feed ratio are $180^{\circ} \mathrm{C}$ and 1.1 , respectively.
\end{abstract}

Keywords: Ultrasonic-assisted technique, acetylene hydrochlorination, vinyl chloride monomer, gold catalyst. 


\section{Introduction}

Polyvinyl chloride (PVC) is one of the most widely-produced plastics. Its demand is continuously increasing worldwide. The volume of PVC world market reached 34 million tons in year 2008. Moreover, the PVC demand is expected to be totally more than 40 million tons in the year 2016 [1]. PVC is commercially produced from polymerization of vinyl chloride monomer ( $\mathrm{VCM}$ ), which is manufactured industrially via dehydrochlorination of dichloroethane (ethylene-based process) or hydrochlorination of acetylene (acetylene-based process). In China, the PVC capacity has increased more than $20 \%$ annually since 2000 and become greater than USA since 2005, becoming the first rank worldwide. Currently PVC production through the acetylene-based process accounts for about $70 \%$ of the total PVC production capacity in China [2]. In commercial acetylene-based process, acetylene gas reacts with anhydrous hydrochloric gas over mercuric chloride supported on activated carbon to produce vinyl chloride monomer (VCM). This reaction is exothermic and highly selective at an optimum reaction temperature of about $170-180^{\circ} \mathrm{C}$ [3-5]. The major problem of this process is arisen from sublimation of mercuric chloride during the production. This does not only affect catalyst deactivation but also cause severe safety and environmental problems [6].

Many researchers have made efforts to investigate new alternative mercuric-free catalysts for acetylene hydrochlorination. Various mercuric-free liquid catalysts such as $\mathrm{Cu}^{+}, \mathrm{Au}^{3+}, \mathrm{Pd}^{2+}$ and $\mathrm{Pt}^{3+}$ have been investigated. $\mathrm{Pt}^{3+}$ and $\mathrm{Pd}^{2+}$ complexes in solution show high activity but they are very unstable [7]. For solid catalysts, gold-based catalyst has been considered as a promising catalyst to replace the mercury-based catalysts among various metal salts i.e., $\mathrm{Au}^{3+}[5,8,9], \mathrm{Cu}^{2+}[10], \mathrm{Pd}^{2+}[11], \mathrm{Pt}^{2+}[12,13]$ and $\mathrm{Bi}^{3+}[14]$. However, their performance is not satisfactory for commercial production due to stability problems. Many researchers indicated that the carbon-supported gold catalyst offers high initial activity; however, it is highly deactivated because the distribution of gold on the support is not well [15-17]. Generally, the gold catalysts have been synthesized using incipient wetness impregnation method. The disadvantage of this preparation is the low active site dispersion the gold active species which can easily aggregate during reaction condition. For the ultrasonic-assisted technique, the ultrasonic wave can enhance good mass transport, emulsification, thermal heating and variety of physical effects on the solids through cavitation phenomena. Then the local temperature and pressure may greatly change the catalyst characteristics; for example, the particle diameter may be decreased, the surface area may be increased and the atom arraangent on the crystal surface of the active substance could be out of order [18, 19]. Therefore, the ultrasonic wave is usually applied to cleaning process; however, many researches have come through investigation on applicatoin of the ultrasonicassisted technique to improve catalyst properties [20-22].

In the present work, Au/C catalysts with high metal dispersion were synthesized by ultrasonic-assisted technique, and their catalytic activity toward the acetylene hydrochlorination was studied and compared to the catalyst prepared by typical incipient wetness impregnation technique.

\section{Experimental}

\subsection{Catalyst Preparation}

$\mathrm{Au} / \mathrm{C}$ catalyst was firstly prepared by conventional incipient wetness impregnation technique using aqua regia as a solvent [23]. The activated carbon support (coconut shell based and supplied by Carbokarn) was initially washed with dilute aqueous $\mathrm{HCl}(1 \mathrm{M})$ (Qrec $\mathrm{HCl} \mathrm{37 \% )}$ to eliminate impurities of acetylene hydrochlorination such as $\mathrm{Na}$ or Fe. The activated carbon support was cleaned up and filtered by distilled water and dried overnight at $110^{\circ} \mathrm{C}$ in an oven. A solution of $\mathrm{HAuCl}_{4} \times \mathrm{xH} 2 \mathrm{O}$ (Sigma-Aldrich: $50 \%$ gold assay) in aqua regia solvent (mixture of $\mathrm{HCl}$ (Qrec $\mathrm{HCl} 37 \%$ ): $\mathrm{HNO}_{3}$ (Qrec $\mathrm{HNO}_{6}$ 67\%) = 3:1) was added dropwisely to the acid-washed activated carbon under stirring. Then the doped catalyst was dried overnight at $110^{\circ} \mathrm{C}$ in the oven (CI sample). Alternatively, the ultrasonic wave was applied to the catalyst synthesis during the active species doping step. The $\mathrm{HAuCl}_{4}$ solution and prepared activated carbon support were mixed by ultrasonic wave in an ultrasonic bath (Crest Ultrasonic Model: 275HTAE 42-45 kHz) controlled at $45-50^{\circ} \mathrm{C}$ for a given driven time. Then the doped catalyst was dried overnight at $110^{\circ} \mathrm{C}$ in the oven (UL sample). 


\subsection{Catalyst Characterization}

X-Ray Diffraction (XRD) was used to investigate the crystalline characteristics of the catalysts. The XRD spectra of catalysts were measured using a SIEMENS D5000 X-ray diffractometer, using a $\mathrm{Cu} \mathrm{K} \alpha$ radiation source with a nickel filter, for $2 \theta$ angles ranging from $20^{\circ}$ to $80^{\circ}$. Temperature-programmed reduction (TPR) was used to determine the reduction temperature of $\mathrm{Au}^{3+}$. This analysis was carried out using a Micromeritics Chemisorb 2750 pulse chemisorption analyzer, with $10 \% \mathrm{H}_{2}$ in $\mathrm{Ar}$ as a reducer and a temperature ramp of 30 to $400^{\circ} \mathrm{C}$ (ramp rate $=10^{\circ} \mathrm{C} / \mathrm{min}$, flow $=50 \mathrm{ml} / \mathrm{min}$ and held at final temperature for $30 \mathrm{~min}$ at $\left.400^{\circ} \mathrm{C}\right)[24]$.

\subsection{Catalytic Performance Evaluation}

The catalytic performance of $\mathrm{Au} / \mathrm{C}$ catalyst on acetylene hydrochlorination was tested in a fixed bed reactor (i.d. $=1 / 4$ inch). Anhydrous hydrogen chloride gas $(99.999 \%)$ was dried using $5 \mathrm{~A}$ molecular sieve column, while the acetylene gas $(99.99 \%)$ was pretreated by molecular sieve $13 \mathrm{X}$ to remove major inhibition impurities (i.e. acetone and moisture). At the starting of the experiment, the reactor containing the catalyst was dried using nitrogen supplied at $120^{\circ} \mathrm{C}$ for $30 \mathrm{~min}$ and was then activated with a mixture of nitrogen and hydrogen chloride at a temperature of $160^{\circ} \mathrm{C}$ for 1 hour. Then the catalyst bed was heated up to a desired temperature under diluted $\mathrm{HCl}$ flow at reaction concentration. A mixture of acetylene and hydrochloride was then fed with a molar ratio of 1:1.1 for a period of 3hours. The exit gas from the reactor was passed through a sodium hydroxide solution to eliminate any unreacted hydrogen chloride gas. The gaseous products were analyzed using an on-line Shimadzu GC2014 gas chromatography with a flame ionization detector equipped with an RTX alumina column. Acetylene conversion and VCM selectivity were calculated from mass balances. The conversion was calculated as the ratio of the amount of remaining acetylene divided by the amount of feed acetylene.

\section{Results and Discussion}

Generally, the gold catalysts used in this reaction have been synthesized using incipient wetness impregnation method. Our previous work [23] demonstrated by TEM measurements that the CI sample has poor metallic dispersion on catalyst whereas the UL sample has excellent metallic. Typically, the properties of catalysts and their activities are in close relationship to the degree of metal dispersion. Thus, enhancing dispersion of Au catalyst on activated support should improve the catalytic performance. In this study, the amount of gold loading on catalyst is controlled at $1 \% \mathrm{wt} \mathrm{Au} / \mathrm{C}$, following the literatures $[8,15]$ and the effect of ultrasonic driven time of the UL catalyst synthesis on catalyst characteristics (measured by $\mathrm{XRD}$ and TPR) and catalytic activity of the acetylene hydrochlorination reaction is determined and compared with those of the catalyst prepared by using conventional impregnation method.

The results of X-ray diffraction (XRD) patterns of CI and UL samples at various driven times are shown in Fig. 1(a). The results show that all of fresh CI and UL samples have the XRD patterns similar to pure carbon support (CK sample) as the crystalline of $\mathrm{Au}^{3+}$ cannot be detected by this technique or with insignificant $\mathrm{Au}^{0}$ reflection detectable [24]. However, the XRD spectra of used catalysts are found the peaks of $\mathrm{Au}^{0}$ reflection. The results can confirm that one reason of catalyst deactivation phenomena is the reduction of gold active species from $\mathrm{Au}^{3+}$ to $\mathrm{Au}^{0}$ as shown in Fig. 1(b). In the $\mathrm{Au} / \mathrm{C}$ catalysts, the typical peaks of $\mathrm{Au}^{0}$ were observed at $2 \theta=38.2,44.4,64.7$ and 77.7 degree, those peaks were assigned to the diffraction lines of [111], [200], [220] and [311] planes of gold [25]. 

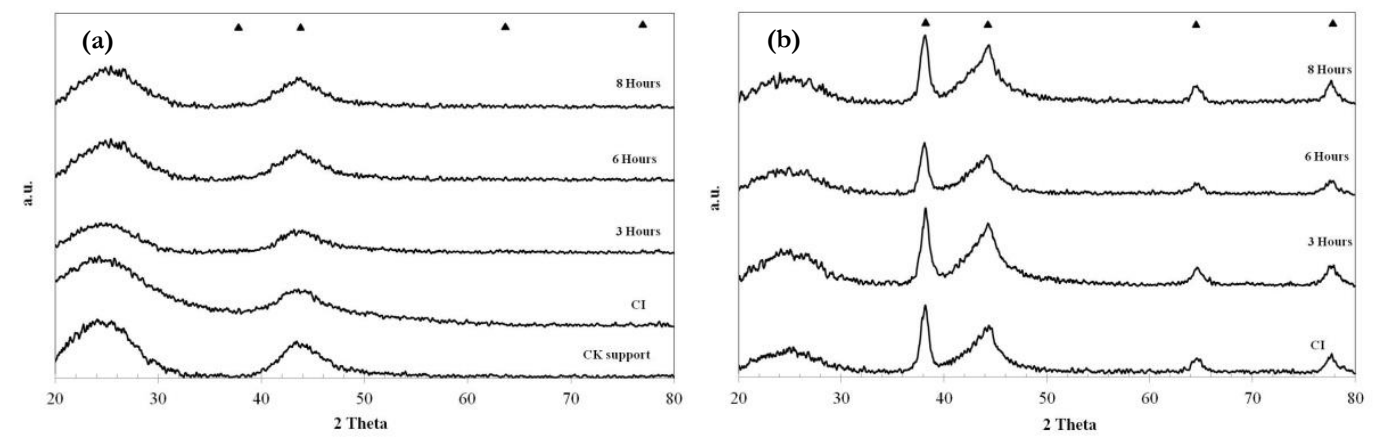

Fig. 1. X-Ray Diffraction (XRD) spectra of different driven time ultrasonic-assisted samples compared with pure carbon support (CK support) and conventional impregnation (CI). The fresh and used catalysts XRD spectra are shown in figure (a) and (b), respectively. (The triangle represents the $\mathrm{Au}^{0} \mathrm{XRD}$ peak position) [25]

Figure 2 shows the temperature programmed reduction (TPR) results of CI sample and UL samples with various driven times. The reduction temperature peaks of $\mathrm{Au} / \mathrm{C}$ of the UL samples are lower than the CI sample $\left(280^{\circ} \mathrm{C}\right)$. Among the UL samples, the catalyst with 6 hours driven time shows the lowest temperature reduction (around $230^{\circ} \mathrm{C}$ ). Generally, the temperature reduction peak is represented the reduction ability of solid catalyst. This should indicate that the opportunities of $\mathrm{Cl}^{-}$supply of the UL samples are better than the CI sample [25]. This hypothesis will be confirmed by catalytic performance results.

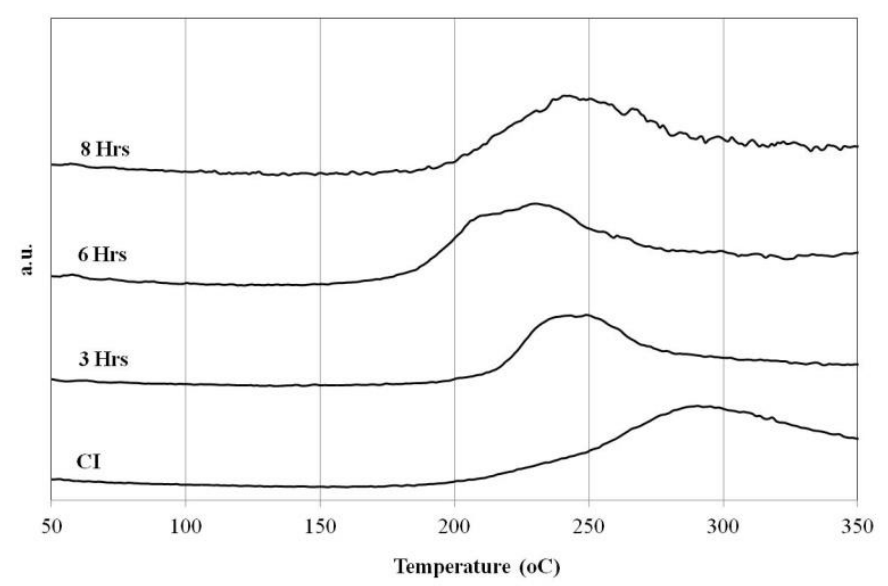

Fig. 2. $\mathrm{H}_{2}$-TPR profiles of gold catalysts synthesized by ultrasonic-assisted technique.

The catalytic performance results of UL samples with different ultrasonic driven times and comparing with CI sample are shown in Fig. 3. The bars represent the differential percentage of acetylene conversion between the first and the third hour operation when the dashed-line bar is the first hour acetylene conversion and the solid-line bar is the third hour data. Moreover, the line shows the average deactivation rate for the reaction period of 3 hours. The results show that the initial acetylene conversion (first hour) of the sample of three hours driven time is highest while the sample of six hours driven time shows the lowest deactivation rate. However, the values are still better than that of the CI sample. These results are related with the reduction temperature results shown in Fig. 2. This relationship can be confirmed by the proposed mechanism from Wang et al.; 2010 [26], who revealed that $\mathrm{C}_{2} \mathrm{H}_{2}$ complex adsorbed on gold active species via Eley-Rideal mechanism reacts with hydrogen chloride in gas phase to produce vinyl chloride monomer. Thus, the catalyst performance is related with abilities of supplying $\mathrm{Cl}-$ from catalyst or reduction ability as related with TPR results in Fig. 2. From the point of view of commercial operation, the catalyst stability is the most important parameter. Thus, the six hours driven time is the suitable time for catalyst preparation by ultrasonic-assisted technique. Again, the stability of the UL samples is better than that of the CI sample. The ultrasonic wave was reported to help homogeneously distribute metal inside the porous material with narrow size distribution [27]. This can be confirms the superior catalytic performance of $\mathrm{Au} / \mathrm{C}$ achieved by 
the use of the ultrasonic-assisted technique for catalyst preparation. However, the acoustic cavitaion phenomena cause higher surface area but it can accelerate free radicals to oxidize the metal surface by formation of a thin oxide layer [28]. Hence, the catalysts can lose the $\mathrm{Cl}^{-}$radicals during cavitation.

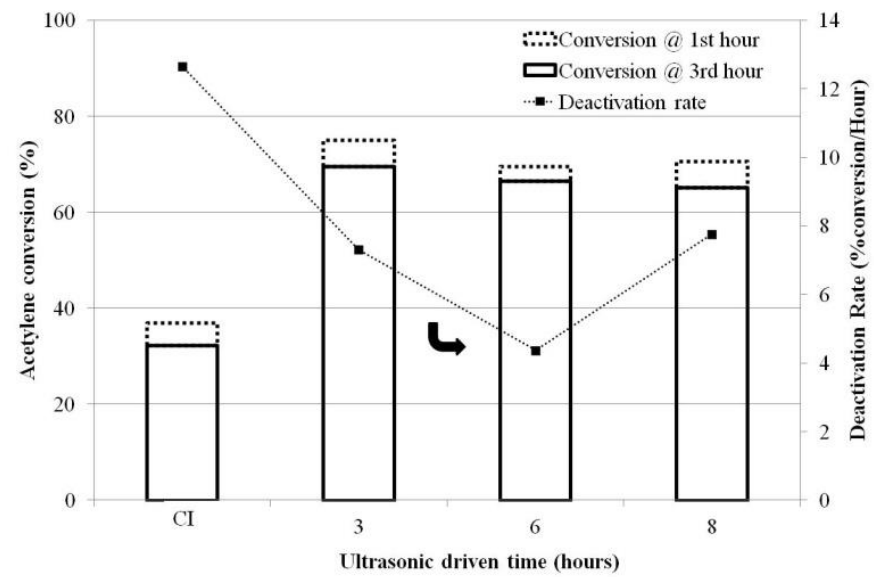

Fig. 3. \%Acetylene conversion of samples prepared by using various ultrasonic driven times and comparing with $\mathrm{CI}$ sample $\left(T=180^{\circ} \mathrm{C}\right.$, ambient pressure and $\mathrm{HCl} / \mathrm{C}_{2} \mathrm{H}_{2}$ ratio $\left.=1.1\right)$.

Figure 4 shows the effect of operating temperature on the acetylene conversion. Commercially, the reactors packed with mercury-based catalyst are operated at a milder condition of $130-180^{\circ} \mathrm{C}$ because the sublimation of mercuric active species becomes significant at temperature above $180^{\circ} \mathrm{C}$ [29]. In this study, three temperature levels of 160,170 and $180^{\circ} \mathrm{C}$ are considered. The results indicate that the operation at $T=180^{\circ} \mathrm{C}$ shows the best catalytic activity. For operation at $T=160$ and $170^{\circ} \mathrm{C}$, very low initial activities are observed; however, they progressively increase with reaction time. The change in catalytic activity with time is likely to be due to the change in size of gold catalyst by sintering. It was reported earlier that there is an optimum size of gold to catalyze the reaction $[23,30]$.

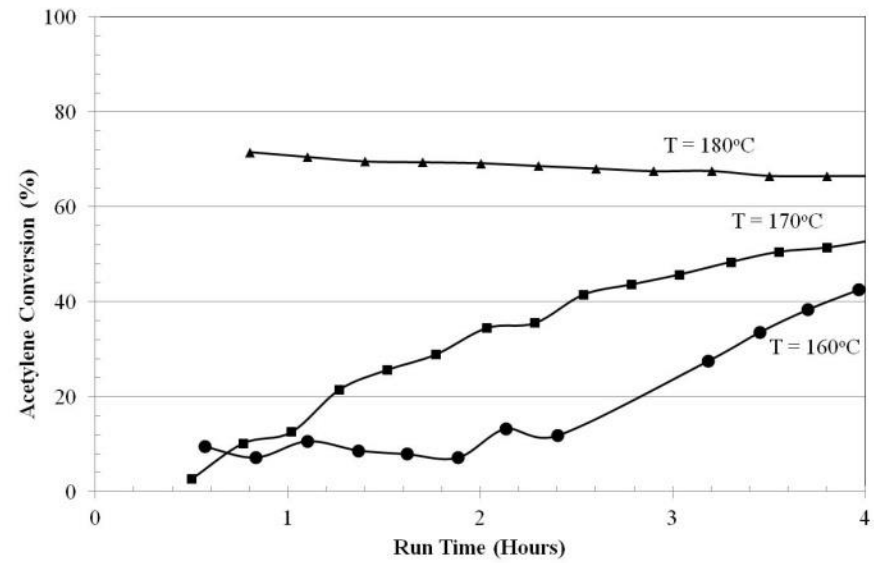

Fig. 4. Effect of reaction temperature on $\%$ acetylene conversion for catalyst prepared with 6 hours driven time (ambient pressure).

Figure 5 shows the catalytic performance for various $\mathrm{HCl} / \mathrm{C}_{2} \mathrm{H}_{2}$ feed ratios. The results indicate that increasing $\mathrm{HCl} / \mathrm{C}_{2} \mathrm{H}_{2}$ could increase conversion and decrease deactivation rate. The order of catalyst deactivation rate is $0.4>0.7>1.1 \mathrm{HCl} / \mathrm{C}_{2} \mathrm{H}_{2}$ feed ratio while the initial activity of all catalysts are almost similar. Initially, the $\mathrm{Au} / \mathrm{C}$ catalyst is fulfilled chloride ion then it will be lost chloride ion from active species during reaction and regenerated by $\mathrm{HCl}$ in feed stream. This is because $\mathrm{C}_{2} \mathrm{H}_{2}$ acts as the reductive or deactivated substance whereas $\mathrm{HCl}$ plays an oxidative or regenerating role [17]. However, the excessive $\mathrm{HCl}$ in feed is undesirable as it would demand significant effort to remove the unreacted $\mathrm{HCl}$ in the downstream process. It was recommended to operate the reaction at a ratio less than $1.5[15,25]$. In addition, further works to study catalyst regeneration by using aqua regia solution or $\mathrm{HCl} / \mathrm{Cl}_{2}$ on-line gas would help explore the reusability of the $\mathrm{Au} / \mathrm{C}$ catalyst. 


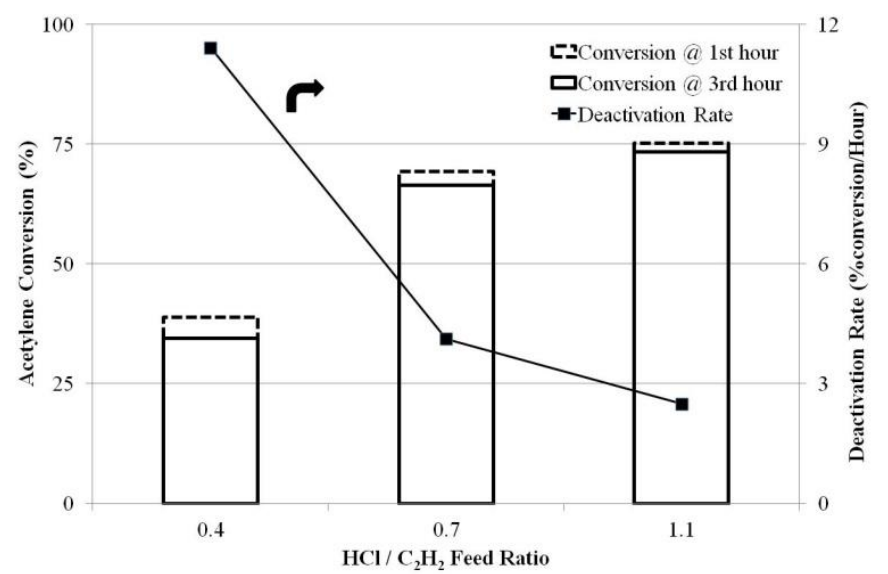

Fig. 5. Effect of $\mathrm{HCl} / \mathrm{C}_{2} \mathrm{H}_{2}$ feed ratio on $\%$ acetylene conversion and \% VCM selectivity at steady state $\left(T=180^{\circ} \mathrm{C}\right.$ and ambient pressure).

\section{Conclusion}

The performance of gold catalyst supported on activated carbon for acetylene hydrochlorination could be improved by changing the catalyst synthesis technique. It was demonstrated that the use of ultrasonicassisted technique could alter the reduction ability of the catalyst. The higher catalytic activity and stability can be enhanced. The suitable condition of this reaction is at reaction temperature of $180^{\circ} \mathrm{C}$ and $\mathrm{HCl} / \mathrm{C}_{2} \mathrm{H}_{2}$ feed ratio of 1.1.

\section{Acknowledgement}

The financial support from Thai Plastic and Chemicals Public Company Limited is gratefully acknowledged.

\section{References}

[1] E. Martin, (2008). Ceresana research releases new comprehensive PVC market study. [Online]. Available: http://www.newswiretoday.com/news/42864/

[2] J. Zhang, N. Liu, W. Li, and B. Dai, "Progress on cleaner production of vinyl chloride monomers over non-mercury catalysts," Front. Chem. Sci. Eng., vol. 5, pp. 514-520, 2011.

[3] S. A. Mitchenko and E. V. Khomutov, A. A. Shubin, and Y. M. Shul'ga, "Catalytic hydrochlorination of acetylene by gaseous $\mathrm{HCl}$ on the surface of mechanically pre-activated $\mathrm{K}_{2} \mathrm{PtCl}_{6}$ salt," J. Mol. Catal. A: Chem., vol. 212, pp. 345-352, 2004.

[4] G. J. Hutchings and D. T. Grady, "Hydrochlorination of acetylene: The effect of mercuric chloride concentration on catalyst life," Appl. Catal., vol. 17, pp. 155-160, 1985.

[5] G. J. Hutchings, "Gold catalysis in chemical processing," Catal. Today, vol. 72, pp. 11-17, 2002.

[6] G. Hutchings, "Reactions of alkynes using heterogeneous and homogeneous cationic gold catalysts," Top. Catal., vol. 48, pp. 55-59, 2008.

[7] S. A. Mitchenko, T. V. Krasnyakova, and I. V. Zhikharev, "Catalytic hydrochlorination of acetylene on mechanochemically-activated $\mathrm{K}_{2} \mathrm{PdCl}_{4}$," Theor. Exp. Chem., vol. 44, pp. 316-319, 2008.

[8] B. Nkosi, M. D. Adams, N. J. Coville, and G. J. Hutchings, "Hydrochlorination of acetylene using carbon-supported gold catalysts: A study of catalyst reactivation," J. Catal., vol. 128, pp. 378-386, 1991.

[9] G. J. Hutchings, "Catalysis by gold," Catal. Today, vol. 100, pp. 55-61, 2005.

[10] J. Ma, S. Wang, and B. Shen, "Study on the effects of acetylene on an $\mathrm{Au}-\mathrm{Cu} / \mathrm{C}$ catalyst for acetylene hydrochlorination using Monte Carlo and DFT methods," Reac. Kinet. Mech. Cat., vol. 110, no. 1, pp. 177-186, 2013. doi: 10.1007/s11144-013-0583-0 
[11] Q. L. Song, S. J. Wang, B. X. Shen, and J. G. Zhao, "Palladium-based catalysts for the hydrochlorination of acetylene: Reasons for deactivation and its regeneration," Pet. Sci. Technol., vol. 28, pp. 1825-1833, 2010.

[12] R. S. Mitchenko, A. A. Shubin, T. V. Krasnyakova, "Mechanism of the catalytic action of the mechanoactivated salt $\mathrm{K}_{2} \mathrm{PtCl}_{4}$ in the gas-phase hydrochlorination of acetylene," Theor. Exp. Chem., vol. 42, pp. 314-319, 2006.

[13] S. A. Mitchenko, T. V. Krasnyakova, R. S. Mitchenko, and A. N. Korduban, "Acetylene catalytic hydrochlorination over powder catalyst prepared by pre-milling of $\mathrm{K}_{2} \mathrm{PtCl}_{4}$ salt," J. Mol. Catal. A: Chem., vol. 275, pp. 101-108, 2007.

[14] K. Zhou, J. Jia, X. Li, X. Pang, C. Li, J. Zhou, G. Luo, and F. Wei, "Continuous vinyl chloride monomer production by acetylene hydrochlorination on $\mathrm{Hg}$-free bismuth catalyst: From lab-scale catalyst characterization, catalytic evaluation to a pilot-scale trial by circulating regeneration in coupled fluidized beds," Fuel Process. Technol., vol. 108, pp. 12-18, 2013.

[15] B. Nkosi, N. J. Coville, G. J. Hutchings, M. D. Adams, J. Friedl, and F. E. Wagner. "Hydrochlorination of acetylene using gold catalysts: A study of catalyst deactivation," J. Catal., vol. 128, pp. 366-377, 1991.

[16] G. J. Hutchings and M. Haruta, "A golden age of catalysis: A perspective," Appl. Catal. A., vol. 291, pp. 2-5, 2005.

[17] M. Conte, A. F. Carley, C. Heirene, D. J. Willock, P. Johnston, A. A. Herzing, C. J. Kiely, and G. J. Hutchings, "Hydrochlorination of acetylene using a supported gold catalyst: A study of the reaction mechanism," J. Catal., vol. 250, pp. 231-239, 2007.

[18] V. Belova, H. Mohwald, and D. G. Shchukin, "Sonochemical intercalation of preformed gold nanoparticles into multilayered clays," Langmuir, vol. 24, pp. 9747-9753, 2008.

[19] C. Zhenxing, L. Honggui, and W. Lingsen, "Activity enhancement of vanadium catalysts with ultrasonic preparation process for the oxidation of sulfur dioxide," J. Nat. Gas Chem., vol. 12, pp. 139$144,2003$.

[20] K. Zhang, F. J. Zhang, M. L. Chen, and W. C. Oh, "Comparison of catalytic activities for photocatalytic and sonocatalytic degradation of methylene blue in present of anatase TiO2-CNT catalysts," Ultrason. Sonochem., vol. 18, pp. 765-772, 2011.

[21] J. Gao, R. Jiang, J. Wang, B. Wang, K. Li, P. Kang, and Y. Li, X. Zhang, "Sonocatalytic performance of Er3+:YAlO3/TiO2-Fe2O3 in organic dye degradation," Chem. Eng. J., vol. 168, pp. 1041-1048, 2011.

[22] P. He, L. Song, X. Wu, H. Tian, Q. Wei, J. Ye, L. Zhang, Y. Cui, and Y. Wang, "Fabrication and sonocatalytic property of $\mathrm{AgPO}_{3}$ microsphere," Ultrason. Sonochem., to be published.

[23] W. Wittanadecha, N. Laosiripojana, A. Ketcong, N. Ningnuek, P. Praserthdam, and S. Assabumrungrat, "Development of $\mathrm{Au} / \mathrm{C}$ catalysts produced by microwave and ultrasonic assisted techniques for use in acetylene hydrochlorination," submitted for publication.

[24] N. Aldea, P. Marginean, V. Rednic, S. Pintea, B. Barz, A. Gluhoi, B. E. Nieuwenhuys, Y. N. Xie, F. Aldea, and M. Neumann, "Crystalline and electronic structure of gold nanoclusters determined by EXAFS, XRD and XPS methods," J. Optoelectron. Adv. Mater., vol. 9, pp. 1555-1560, 2007.

[25] D. Boyd, S. Golunski, G. R. Hearne, T. Magadzu, K. Mallick, M. C. Raphulu, A. Venugopal, and M. S. Scurrell, "Reductive routes to stabilized nanogold and relation to catalysis by supported gold," Appl. Catal. A: General, vol. 292, pp. 76-81, 2005.

[26] S. Wang, B. Shen, and Q. Song, "Kinetics of acetylene hydrochlorination over bimetallic Au-Cu/C catalyst," Catal. Lett., vol. 134, pp. 102-109, 2010.

[27] N. Pazos-Perez, J. Schäferhans, E. V. Skorb, A. Fery, and D. V. Andreeva, "Ultrasound driven formation of metal-supported nanocatalysts," Microporous Mesoporous Mater., vol. 154, pp. 164-169, 2012.

[28] E. Skorb, H. Möhwald, T. Irrgang, A. Fery, and D. V. Andreeva, "Ultrasound-assisted design of metal nanocomposites," Chem Comm., vol. 46, pp. 7897-7899, 2010.

[29] G. J. Hutchings and D. T. Grady, "Effect of drying conditions on carbon supported mercuric chloride catalysts," Appl. Catal., vol. 16, pp. 411-415, 1985.

[30] M. Conte, C. J. Davies, D. J. Morgan, T. E. Davies, D. J. Elias, A. F. Carley, P. Johnston, and G. J. Hutchings, "Aqua regia activated Au/C catalysts for the hydrochlorination of acetylene," J. Catal., vol. 297, pp. 128-136, 2013. 
